University of Nebraska - Lincoln

DigitalCommons@University of Nebraska - Lincoln

Food and Drug Administration Papers

U.S. Department of Health and Human Services

2019

\title{
At risk alcohol consumption with smoking by national background: Results from the Hispanic community health study/ study of Latinos
}

Frank C. Bandiera

Eliseo J. Pérez-Stable

Folefac Atem

Raul Caetano

Denise C. Vidot

See next page for additional authors

Follow this and additional works at: https://digitalcommons.unl.edu/usfda

Part of the Dietetics and Clinical Nutrition Commons, Health and Medical Administration Commons, Health Services Administration Commons, Pharmaceutical Preparations Commons, and the Pharmacy Administration, Policy and Regulation Commons

This Article is brought to you for free and open access by the U.S. Department of Health and Human Services at DigitalCommons@University of Nebraska - Lincoln. It has been accepted for inclusion in Food and Drug Administration Papers by an authorized administrator of DigitalCommons@University of Nebraska - Lincoln. 


\section{Authors}

Frank C. Bandiera, Eliseo J. Pérez-Stable, Folefac Atem, Raul Caetano, Denise C. Vidot, Marc D. Gellman, Elena L. Navas-Nacher, Jianwen Cai, Gregory Talavera, Neil Schneiderman, and Robert Kaplan 


\title{
At risk alcohol consumption with smoking by national background: Results from the Hispanic community health study/study of Latinos
}

\author{
Frank C. Bandiera ${ }^{\mathrm{a}, *}$, Eliseo J. Pérez-Stable ${ }^{\mathrm{j}}$, Folefac Atem ${ }^{\mathrm{b}}$, Raul Caetano ${ }^{\mathrm{c}}$, Denise C. Vidot $^{\mathrm{d}}$, \\ Marc D. Gellman ${ }^{\mathrm{e}}$, Elena L. Navas-Nacher ${ }^{\mathrm{f}}$, Jianwen Cai ${ }^{\mathrm{g}}$, Gregory Talavera ${ }^{\text {h }}$, Neil Schneiderman ${ }^{\mathrm{e}}$, \\ Robert Kaplan ${ }^{\mathrm{i}}$
}

${ }^{a}$ Food and Drug Administration, Center for Tobacco Products, United States of America

${ }^{\mathrm{b}}$ University of Texas School of Public Health, United States of America

${ }^{\mathrm{c}}$ Pacific Institute for Research and Evaluation, United States of America

${ }^{\mathrm{d}}$ School of Nursing and Health Studies, University of Miami, United States of America

${ }^{\mathrm{e}}$ Department of Psychology, University of Miami, United States of America

${ }^{\mathrm{f}}$ University of Illinois at Chicago, United States of America

${ }^{\mathrm{g}}$ Collaborative Studies Coordinating Center, Department of Biostatistics, University of North Carolina at Chapel Hill, United States of America

${ }^{\mathrm{h}}$ Division of Health Promotion and Behavioral Science, San Diego State University, United States of America

${ }^{\mathrm{i}}$ Department of Epidemiology and Population Health, Albert Einstein College of Medicine, United States of America

${ }^{\mathrm{j}}$ Division of Intramural Research, National Heart and Lung Blood Institute, and National Institute on Minority Health and Health Disparities, National Institutes of Health,

United States of America

\section{H I G H L I G H T S}

- Caribbean Latinas were more likely to smoke and binge drink.

- Central and South American men were more likely to co-use.

- Acculturation was not positively associated with co-use of at-risk drinking and smoking.

\section{A R T I C L E I N F O}

\section{Keywords:}

Smoking

Alcohol

Hispanics/Latinos

\begin{abstract}
A B S T R A C T
Introduction: Tobacco smoking and binge or excess drinking are unhealthy behaviors that frequently co-occur. Studies of Hispanics/Latinos have mostly been of Mexican Americans although there are substantial differences in smoking and drinking by heritage background. Associated with co-use by 5 subpopulations.

Methods: Cross-sectional data of 16,412 Hispanics/Latinos from Miami, the Bronx, Chicago and San Diego collected between 2008 and 2011 as part of the HCHS/SOL were analyzed. Smoking and alcohol consumption and demographic data were measured by self-report. Prevalence of smoking and alcohol consumption and co-use were reported. Logistic regression models examined the odds of co-use of smoking and binge or excess alcohol use by Hispanic/Latino background group.

Results: Men of Cuban (10.3\%), Puerto Rican (8.9\%), and Mexican (8.9\%) background had the highest prevalence of co-use of smoking and binge drinking compared to men of Central American (6.1\%) and Dominican (6.6\%) background. Women of Dominican (16.4\%) and Puerto Rican (19.7\%) background had the highest prevalence of binge drinking compared to women of Central American (10\%) and Cuban (8\%) background and Puerto Rican (34.1\%) and Cuban (21.8\%) women were the most likely to report current smoking compared to women of Central American (8.3\%) and Mexican (10.4\%) background. Acculturation was not associated with couse among men and women. Elevated depressive symptoms were positively associated with smoking and binge drinking among men, $\mathrm{OR}=1.5$ [1.2-2.0], and women, $\mathrm{OR}=1.5$ [1.1-2.2]. Puerto Rican women had increased odds of co-use of smoking and binge or excess drinking compared to Mexican American women, OR $=3.2$ [1.5-6.6].
\end{abstract}

\footnotetext{
Abbreviations: HCHS/SOL, Hispanic Community Health Study/Study of Latinos; IRB, Institutional Review Board; CESD, Center for Epidemiologic Studies Depression Scale; NIAAA, National Institute on Alcohol Abuse and Alcoholis

* Corresponding author at: 5323 Harry Hines Blvd., V8.112, White Oak, MD 75390-9128, United States of America.

E-mail address: frank.bandiera@fda.hhs.gov (F.C. Bandiera).
} 
Conclusions: Puerto Rican and Dominican Latinas and Central American and South American men have a higher prevalence of co-use.

\section{Introduction}

Hispanics/Latinos are faced with factors that may lead to co-use of cigarette smoking and at-risk alcohol consumption (defined as excess intake or binge drinking) such as poverty, stress related to immigration, and/or discrimination. Previous studies in this area have categorized Hispanics/Latinos into a single population group, which is a limitation due to the diversity of health behaviors by heritage background. There is substantial variation of smoking and at-risk alcohol consumption patterns among Hispanics/Latinos by gender and Hispanic/Latino background. Men and women of Puerto Rican background have been reported to have the highest prevalence of both smoking and at-risk alcohol use compared to other Hispanic/Latinos. Cuban Americans have the highest prevalence of smoking but the lowest rate of at risk alcohol use among Hispanic/Latino subpopulations (Caetano, Ramisetty-Mikler, \& Rodriguez, 2009; Kaplan, Bangdiwala, Barnhart, et al., 2014; Perez-Stable, Ramirez, Villareal, et al., 2001; Vaeth, Caetano, \& Rodriguez, 2012). Mexican Americans, on the other hand, are reported to have the lowest prevalence of smoking, and among the men, the highest prevalence of at risk alcohol use(Caetano et al., 2009; Chartier \& Caetano, 2010; Kaplan et al., 2014; Perez-Stable et al., 2001; Ramisetty-Mikler, Caetano, \& Rodriguez, 2010; Vaeth, Caetano, Mills, \& Rodriguez, 2012; Vaeth, Caetano, \& Rodriguez, 2012). Given these differences by national background, this is significant to the field of substance use because identifying which groups are more likely to couse smoking and alcohol would help prevention and treatment efforts focus on specific population groups. Further, establishing how sociocultural factors, such as acculturation and birthplace, and elevated depressive symptoms are associated with co-use is significant since interventions can be tailored to more acculturated Hispanics/Latinos, country of birth, and depressed mood.

Studies of acculturation to the U.S. mainstream have shown association with higher prevalence of smoking among Latinas(Kaplan et al., 2014; Marin, Perez-Stable, \& Marin, 1989; Perez-Stable et al., 2001); however, among men, acculturation is either not significantly associated with smoking or somewhat protective (Kaplan et al., 2014; Marin et al., 1989; Perez-Stable et al., 2001). Normative norms, such as liberal attitudes towards drinking, play a role on why the association between acculturation and at-risk drinking is positive among Latina women. Latina women do not perceive that they drink as much as White women; however, they tend to have heavy drinking patterns. Zemore and Vaeth et al. also found that stress, such as elevated depressive symptoms, do not play a consistent role in the association between acculturation and at-risk drinking among Latina women (Vaeth, WangSchweig, \& Caetano, 2017; Zemore, 2005). Although the association between acculturation and at risk alcohol use has been mixed among Hispanics/Latinos, a large recent meta-analysis found a small effect of increased acculturation and at risk alcohol consumption, especially among women versus men (Lui \& Zamboanga, 2018). How acculturation affects the combination of smoking and at-risk alcohol use by Hispanic/Latino background remains unknown. Other demographic factors such as birthplace and socioeconomic status may also interact with acculturation and influence co-use of cigarettes and at-risk alcohol.

It is well established that elevated depressive symptoms are associated with greater smoking(Bandiera, Arguelles, Gellman, et al., 2015; Prochaska, 2011) and at risk alcohol use (Caetano, 1987; Jetelina, Reingle Gonzalez, Vaeth, Mills, \& Caetano, 2016). A main reason why persons with elevated depressive symptoms use substances, such as smoking and at-risk alcohol use, is because use of these substances provides temporary relief of psychological distress (Khantzian, 1997; Liu, Oshri, \& Duprey, 2018), leading to the assumption that these persons are self-medicating with cigarettes and alcohol (Khantzian, 1997; Liu et al., 2018). As previously mentioned, smoking and alcohol use tend to co-occur, and thus persons may be self-medicating with both cigarettes and alcohol. There is also research suggesting that mental disorders differ among Hispanics/Latinos by national background (Alegria et al., 2007). It is plausible that Hispanics/Latinos with elevated depressive symptoms have different patterns of self-medication or co-use of smoking and alcohol by national background and gender. There is no existing literature on how elevated depressive symptoms are associated with co-use of smoking and at-risk alcohol among Hispanics/ Latinos of different national backgrounds. Although unhealthy behaviors cluster together, there are limited data to examine the co-use of excessive and binge alcohol consumption and cigarette smoking by Hispanic/Latino subpopulations. Further, physical activity has been found to be protective of at-risk alcohol use(Ejsing, Becker, Tolstrup, \& Flensborg-Madsen, 2015; Hallgren, Vancampfort, Lundin, Andersson, \& Andreasson, 2018) and smoking (Pavey, Gartner, Coombes, \& Brown, 2015; Prapavessis et al., 2016). Previous studies have found that physical activity helps lower the amount of drinking among persons with alcohol use disorders (Ejsing et al., 2015; Hallgren et al., 2018). There is also some evidence suggesting that physical activity promotes smoking cessation (Pavey et al., 2015; Prapavessis et al., 2016). How physical activity is associated with co-use of smoking and at-risk drinking is unknown, especially in Hispanic/Latino populations.

Most prior studies have been predominantly of Mexican Americans and there is limited information on co-occurring smoking and at-risk alcohol use patterns among other Hispanic/Latino subpopulations. The National Institutes of Health initiated the Hispanic Community Health Study/Study of Latinos (HCHS/SOL) (https://sites.cscc.unc.edu/hchs/) to study differences in chronic disease and behavior by Hispanic/Latino background group using uniform recruitment protocols in all groups to facilitate comparisons. HCHS/SOL data are unique given the large number of individuals from five different Latin American national origins and recruited from four distinct regions in the U.S. The main objective of this study was to examine the association and co-use between excess and binge alcohol use and tobacco smoking behavior by Hispanic/Latino subpopulations, acculturation, gender, depressive symptoms (Bandiera et al., 2015), and other health-related factors.

\section{Methods}

\subsection{Study design, settings, and individuals}

Data were obtained from the HCHS/SOL, which is an epidemiologic population-based study of health and disease in six Hispanic/Latino background populations in the United States. Individuals were recruited from four sites (the Bronx, NY; Chicago, IL; Miami, FL; and San Diego, CA) and all estimates were age-adjusted to the 2010 U.S. census. A detailed description of the study design and methods and of the sample design and cohort selection were published (Lavange, Kalsbeek, Sorlie, et al., 2010; Sorlie, Aviles-Santa, Wassertheil-Smoller, et al., 2010). At the time of screening, individuals had to self-identify as Hispanic/Latino and be between 18 and 74 years old. The institutional review board (IRB) at each site approved the study protocol and all individuals gave informed consent. This analysis included individuals who attended the baseline exam between 2008 and 2011 and who had sample weights and values for the variables analyzed. Individuals had the option of completing the surveys in either English or Spanish. The total number 
of individuals used in this analysis was 16,415.

\subsection{Measurements}

Age, birthplace in the US 50 states versus not, education (high school graduate, not high school graduate) and gender were collected by self-report. Puerto Ricans born in Puerto Rico were considered not U.S. born for this analysis. Individuals were asked what country they or their families originated from. Persons of South American background were also recruited and individuals reporting heritage from more than country of family origin were categorized as Other.

Physical activity was measured using the World Health Organization Physical Activity Questionnaire (Bull, Maslin, \& Armstrong, 2009). Individuals were grouped in four categories: High (more than the equivalent of $300 \mathrm{~min}$ of moderate-intensity physical activity a week or $>150 \mathrm{~min}$ of vigorous activity), medium (150 min to $300(5 \mathrm{~h})$ of moderate-intensity activity a week (or 75 to $150 \mathrm{~min}$ of vigorous-intensity physical activity a week), low (activity beyond baseline activities of daily living but fewer than $150 \mathrm{~min}(2 \mathrm{~h}$ and $30 \mathrm{~min}$ ) of moderate-intensity physical activity a week or the equivalent amount ( $75 \mathrm{~min}$, or $1 \mathrm{~h}$ and $15 \mathrm{~min}$ ) or inactive (no activity beyond baseline activities of daily living). Individuals who had medium or high levels of physical activity met 2008 guidelines for activity level (www. health.gov/paguidelines/default.aspx). Individuals were also asked if they currently have health insurance or not.

Acculturation was measured using a 10-item Short Acculturation Scale for Hispanics (SASH) adapted from a widely used scale (Marin, Otero-Sabogal, \& Perez-Stable, 1987). HCHS/SOL used the language and social relations subscales to represent acculturation. The SASH scale in HCHS/SOL has excellent internal consistencies for the language subscale (Cronbach $\alpha$ 's $=0.92$ ) and social subscale (Cronbach $\alpha$ 's $=0.73$ ). The language subscale consisted of 6 questions related to language preference (English versus Spanish) on a 5-point Likert-scale ranging from $1=$ Only Spanish to $5=$ Only English and the responses are averaged to define a score. The social relations subscale measures social acculturation with 4 questions related to individuals' social network's ethnicity. A 5-point Likert-scale is assigned to each question with $1=$ All Hispanic/Latino and 5-All non-Hispanic/Latino. The average of these responses was used to define the social relations acculturation score.

Depressive symptoms were measured by a 10 -item Center for Epidemiologic Studies Depression Scale (CESD) which has good predictive accuracy compared to the full-length 20 -item version $(\kappa=0.97)$ with good validity and reliability (Andresen, Malmgren, Carter, \& Patrick, 1994). The CESD in HCHS/SOL has acceptable internal consistencies (Cronbach $\alpha$ 's $=0.80-0.86$ ) across the total sample, language group and national background group. Response format: $0=$ rarely or none of the time, 1 = some or a little of the time, 2 = occasionally or a moderate amount of time, $3=$ all of the time. These responses resulted in a numeric variable with values ranging from 0 to 30 . Elevated depressive symptoms was defined by using a cut point of $\geq 10$ on the CESD (Andresen et al., 1994).

\subsection{Smoking and at-risk alcohol use}

Smoking status was ascertained by first asking if individuals had ever smoked 100 or more cigarettes in their lifetime, and if Yes, then asked if they currently smoke cigarettes ("some days" or "every day"). If individuals answered No to ever having smoked 100 or more cigarettes in their lifetime then they are considered Never Smokers. If individuals have smoked 100 or more cigarettes in their lifetime, but do not currently smoke, then they are considered as Former Smokers. If individuals have smoked 100 or more cigarettes in their lifetime and currently smoke, then they are considered Current Smokers. Current Smokers include smokers who smoked daily or non-daily. Non-smokers included Never Smokers and Former Smokers.
Individuals were asked if they had ever drunk alcohol in their lifetime, and if Yes, then asked if they currently drink alcohol. Individuals who reported no current use of alcohol in the past week were considered at no risk of alcohol use disorder, those with $<14$ drinks in the past week for men and $<7$ drinks in the past week for women were considered at low risk, and high risk use was defined as $\geq 14$ drinks in the past week for men and $\geq 7$ drinks in the past week for women. Being in the high risk use level was defined as excess drinking (NIAAA, 2019a). Binge drinking was defined as drinking four or more (for women) and five or more (for men) standard drinks of wine, beer, or liquor per occasion within a two-hour period in the previous month (NIAAA, 2019b). At risk alcohol consumption was defined as either binge or excess drinking.

\subsection{Statistical analysis}

Weighted prevalence of smoking and alcohol use among men and women were computed using sample weights, which were adjusted, trimmed, and calibrated to the 2010 U.S. Census population age and Hispanic/Latino background distributions for the four geographic study areas. Descriptive statistics were computed by cross-tabs of the main variables by gender. First, we evaluated the co-use between at risk alcohol consumption and smoking status stratified by gender. Within each gender, cross-tabs between co-occurring alcohol consumption and smoking status were computed by age, health insurance, physical activity, Hispanic/Latino background group, birthplace and significant depressive symptoms. Associations of co-occurring binge drinking and smoking and excess drinking and smoking stratified by gender were examined.

Logistic regression models were used with age, U.S. born, depressive symptoms, physical activity, health insurance, language acculturation, social relations acculturation, field center, and Hispanic/Latino background group included in the model to examine the co-use of binge drinking and smoking and excess drinking and smoking. For testing whether Hispanic/Latino background is associated with co-use of smoking and at risk drinking, an overall F-test was conducted first for the null hypothesis that all Hispanic/Latino groups are the same. If the overall F-test is statistically significant at 0.05 level, pairwise comparisons between different groups are then made. Co-use for each Hispanic/Latino background population were calculated. Complex survey procedures were used in all analyses to account for the complex survey sampling design. Analyses were conducted using statistical software (SAS, version 9.2; SAS Institute).

\section{Results}

Demographic characteristics are shown in Table 1. About a third in the target population had not graduated from high school and most were immigrants. A higher proportion of women (33\%) than men (21\%) had a CESD score $\geq 10$. The average number of alcoholic drinks per week for drinkers was more than four times higher for men compared to women (4.6 (95\% CI: 4.3-4.9) versus 1.1 (0.91.2)). Approximately $59 \%$ of women did not currently use alcohol while approximately $36 \%$ of men did not report current alcohol use. Only $3.5 \%$ of women and $8.8 \%$ of men had at risk level use of alcohol.

\subsection{Co-use between smoking and alcohol consumption: bivariate comparisons}

Table 2 shows the prevalence of binge and excess alcohol intake and cigarette smoking status in addition to their respective co-use by each of the demographic characteristics. Binge drinking was more common among Dominican, Puerto Rican, Mexican, compared to Cuban men and Central American men while Cuban and Puerto Rican men were more likely to be current smokers compared to Mexican men. Co-use of binge drinking, and current smoking was highest among Cuban men at $10.3 \%$ 
Table 1

Baseline demographic characteristics, alcohol use and smoking behavior by gender in the target population of HCHS/SOL 2008-2011.

\begin{tabular}{|c|c|c|}
\hline \multirow[t]{2}{*}{ Characteristic } & Women & Men \\
\hline & $\begin{array}{l}\text { Unweighted N } \\
\text { (weighted \%) / mean } \\
(95 \% \mathrm{CI})\end{array}$ & $\begin{array}{l}\text { Unweighted N } \\
\text { (weighted \%) / mean } \\
(95 \% \text { CI) }\end{array}$ \\
\hline Total sample & 9785 & 6528 \\
\hline \multicolumn{3}{|l|}{ Age (years) } \\
\hline $18-24$ & $878(15.8 \%)$ & $787(17.9 \%)$ \\
\hline $25-34$ & $1136(21.1 \%)$ & $946(22.3 \%)$ \\
\hline $35-44$ & $1787(20.9 \%)$ & $1167(21.4 \%)$ \\
\hline $45-54$ & $3051(19.2 \%)$ & $1871(18.5 \%)$ \\
\hline $55-64$ & $2152(13.4 \%)$ & $1308(12.0 \%)$ \\
\hline $65+$ & $831(9.4 \%)$ & $501(7.5 \%)$ \\
\hline \multicolumn{3}{|l|}{ Education } \\
\hline Less than high school & $3768(32.8 \%)$ & $2439(31.7 \%)$ \\
\hline High school or more & $6013(67.1 \%)$ & $4104(68.2 \%)$ \\
\hline \multicolumn{3}{|l|}{ Birthplace } \\
\hline Foreign born & $8189(79.1 \%)$ & $5290(74.9 \%)$ \\
\hline US born & $1604(20.8 \%)$ & $1259(25.0 \%)$ \\
\hline \multicolumn{3}{|l|}{ Field center } \\
\hline Bronx & $2518(30.2 \%)$ & $1600(27.6 \%)$ \\
\hline Chicago & $2313(14.6 \%)$ & $1821(17.0 \%)$ \\
\hline Miami & $2353(28.5 \%)$ & $1724(30.0 \%)$ \\
\hline San Diego & $2651(26.5 \%)$ & $1435(25.2 \%)$ \\
\hline \multicolumn{3}{|l|}{ Depressive symptoms } \\
\hline CESD $<10$ & $6281(66.9 \%)$ & $5034(79.0 \%)$ \\
\hline CESD $\geq 10$ & $3348(33.0 \%)$ & $1396(20.9 \%)$ \\
\hline \multicolumn{3}{|l|}{$\begin{array}{l}\text { Hispanic/Latino background } \\
\text { group }\end{array}$} \\
\hline Dominican & $963(11.5 \%)$ & $510(8.2 \%)$ \\
\hline Central American & $1049(7.4 \%)$ & $683(7.3 \%)$ \\
\hline Cuban & $1250(18.3 \%)$ & $1098(21.8 \%)$ \\
\hline Mexican & $4022(38.1 \%)$ & $2450(36.5 \%)$ \\
\hline Puerto Rican & $1589(15.3 \%)$ & $1139(17.0 \%)$ \\
\hline South American & $635(5.2 \%)$ & $437(4.7 \%)$ \\
\hline Others & $276(3.9 \%)$ & $227(4.2 \%)$ \\
\hline $\begin{array}{l}\text { Acculturation language } \\
\text { subscale mean score }\end{array}$ & $2.0(1.9-2.1)$ & $2.2(2.1-2.3)$ \\
\hline $\begin{array}{l}\text { Acculturation social relations } \\
\text { subscale mean score }\end{array}$ & $2.2(2.1-2.2)$ & $2.2(2.2-2.3)$ \\
\hline \multicolumn{3}{|l|}{ Smoking status } \\
\hline Smoker & $1486(16.4 \%)$ & $1680(26.7 \%)$ \\
\hline Non-smoker & $8304(83.5 \%)$ & $4840(73.2 \%)$ \\
\hline \multicolumn{3}{|l|}{ Alcohol use disorder risk level } \\
\hline No current use in past week & 6097 (59.0) & $2503(36.6)$ \\
\hline Lower risk level use & $3420(37.3)$ & $3497(54.4)$ \\
\hline High-risk level use & $279(3.5)$ & $549(8.8)$ \\
\hline $\begin{array}{l}\text { Average number of drinks per } \\
\text { week for drinkers of } \geq 1 \\
\text { drink in previous week }\end{array}$ & $1.1(0.9-1.2)$ & $4.6(4.3-4.9)$ \\
\hline
\end{tabular}

HCHS/SOL = Hispanic Community Health Study/Study of Latinos; CES$\mathrm{D}=$ Center for Epidemiologic Studies Scale.

The acculturation language subscale consisted of 6 questions related to language preference (English versus Spanish) on a 5-point Likert-scale ranging from $1=$ Only Spanish to $5=$ Only English and the responses are averaged to define a score. A higher score on the scale signifies higher language acculturation.

The acculturation social relations subscale measures social acculturation with 4 questions related to individuals' social network's ethnicity. A 5-point Likertscale is assigned to each question with 1 = All Hispanic/Latino and 5-All nonHispanic/Latino. The average of these responses was used to define the social relations acculturation score. A higher score on the scale signifies higher social relations acculturation.

and lowest among men from South America at 3.6\%. Co-use of excess drinking and smoking was more common with a prevalence of 20.8 among Puerto Ricans compared with any other national background and lowest among Dominican men at $8.4 \%$ but no significant differences by background group. Younger men had a higher prevalence of binge drinking than older men, but the prevalence of excess drinking did not decrease until after age 65. Men ages 25-54 had a higher prevalence of current smoking than older men. US born men had a higher prevalence of binge drinking, excess drinking and current smoking than foreign born men. More sedentary lifestyle was associated with at risk alcohol use and current smoking than physically active lifestyle. There were no differences by health insurance in smoking and at-risk alcohol use.

Dominican and Puerto Rican women had the highest prevalence of binge drinking ( $16.4 \%$ and $19.7 \%$, respectively) and excess drinking than any other national background, and women of Puerto Rican (34.1\%) and Cuban (21.8\%) backgrounds had the highest prevalence of current smoking than any other national background. Women of Dominican and Puerto Rican backgrounds had the highest prevalence of co-use of binge drinking and current smoking at a prevalence of 5.8\% and $4.5 \%$, respectively than any other national background. Puerto Rican women had a much higher prevalence of co-use of excess drinking and smoking than other women (13.4\%). Binge and excess drinking were highest among the youngest age group and declined for each decade. However, smoking was highest for women ages 25-34 and 45-54 and lowest for those 65 or older. US born women and those with elevated depressive symptoms had a higher prevalence of binge drinking, excess drinking and current smoking than foreign born women. More sedentary lifestyle was associated with higher prevalence of binge drinking than physically active lifestyle. There was no difference in binge drinking, excess drinking, current smoking, co-use of binge drinking and smoking, and co-use of excess drinking and smoking by current health insurance among women.

\subsection{Multivariable logistic regression models of smoking and at-risk alcohol co-use}

Table 3 shows the logistic regressions of factors associated with couse binge drinking and smoking, co-use excess drinking and smoking, and co-use of either binge drinking or excess drinking and smoking. Compared to Mexican men (referent), Central and South American men had lower odds of co-use of binge drinking and smoking and either binge drinking and excess drinking and smoking. Older age was associated with lower odds of co-use of binge drinking and smoking and either binge drinking and excess drinking and smoking than younger age. Men with elevated depressive symptoms had greater odds for couse of binge drinking and smoking, co-use of excess drinking and smoking, and either binge drinking and excess drinking and smoking than men without elevated depressive symptoms. Men without current health insurance had greater odds for co-use of binge and excess drinking and smoking and either binge drinking and excess drinking and smoking than men without current health insurance. Languagebased acculturation was not significantly associated with co-use of atrisk alcohol consumption and smoking.

Compared to Mexican women, Puerto Ricans had significant increased odds of co-use of binge and excess drinking and smoking and either binge drinking or excess drinking and smoking. Dominican and Central American women also had significantly higher odds of co-use of excess drinking and current smoking than Mexican women. Age was also inversely associated with co-use of binge and excess drinking and smoking among women and either binge drinking and excess drinking and smoking. Women with elevated depressive symptoms had greater odds for co-use of binge and excess drinking and smoking and either binge drinking or excess drinking and smoking than women without elevated depressive symptoms. Language-based acculturation was not positively associated with co-use of binge drinking and smoking and not with co-use of excess drinking and smoking. Foreign born women had greater odds of co-use of binge drinking and smoking and excess drinking and smoking and either binge drinking or excess drinking and smoking than US born women. 


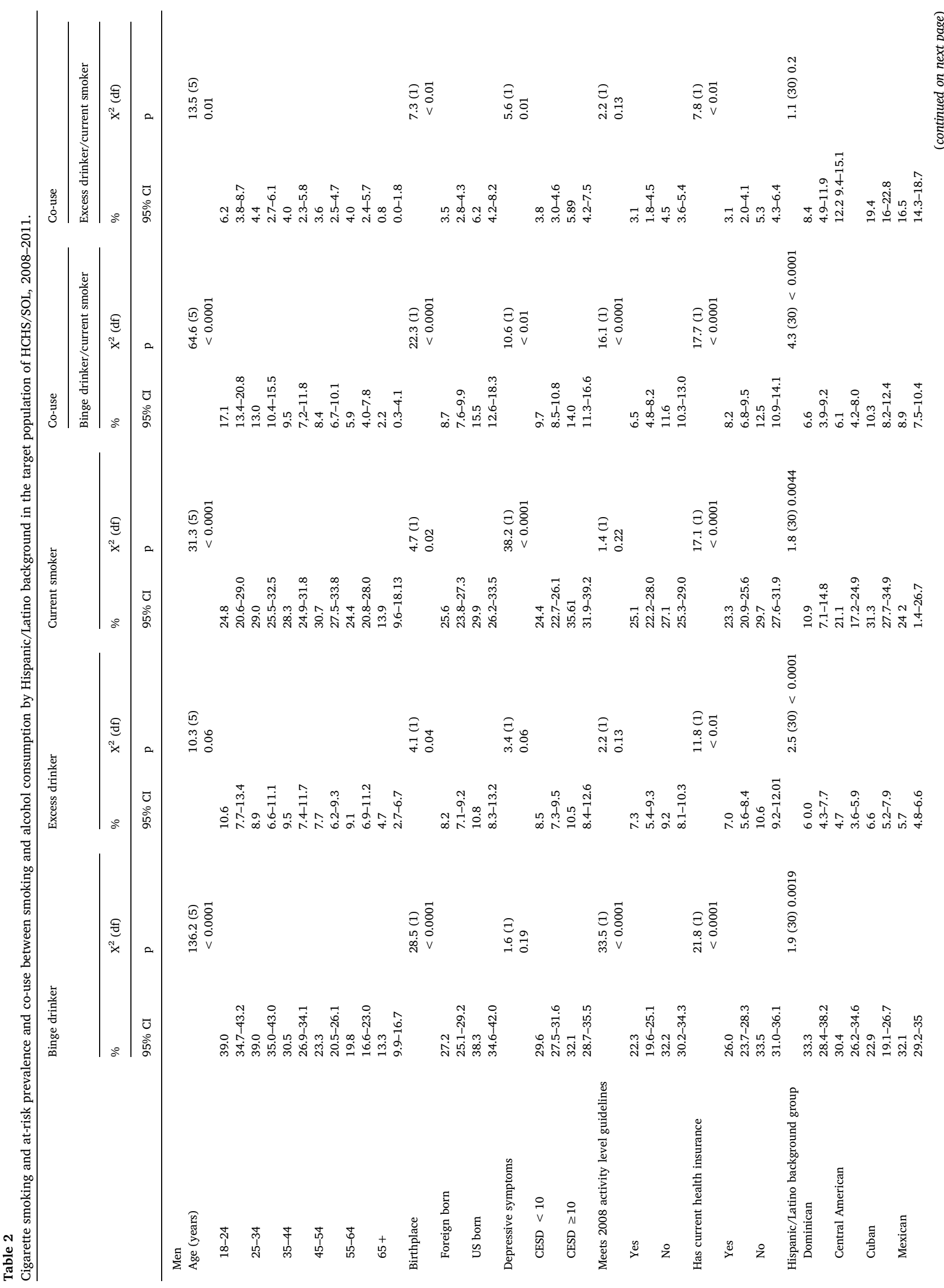




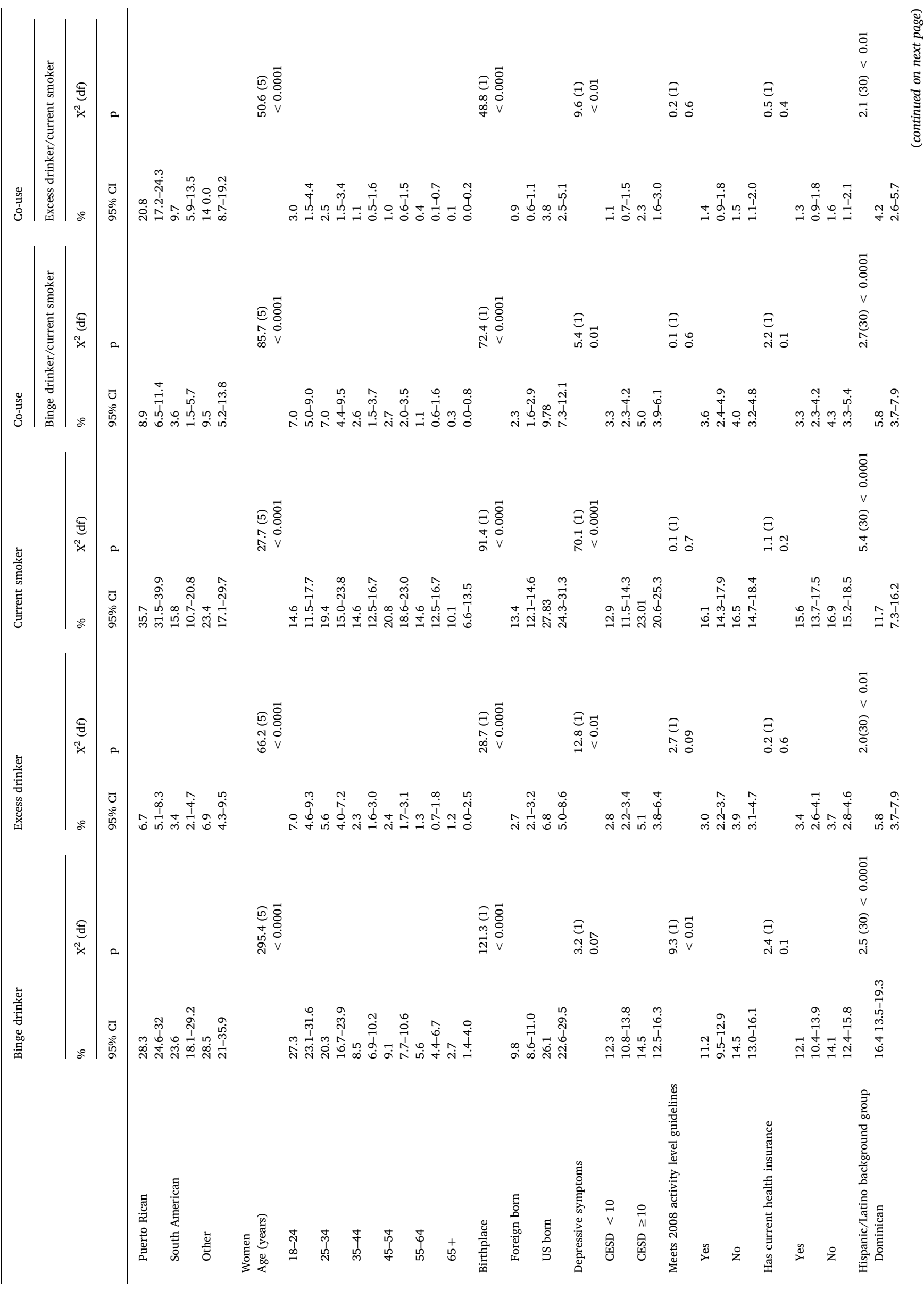




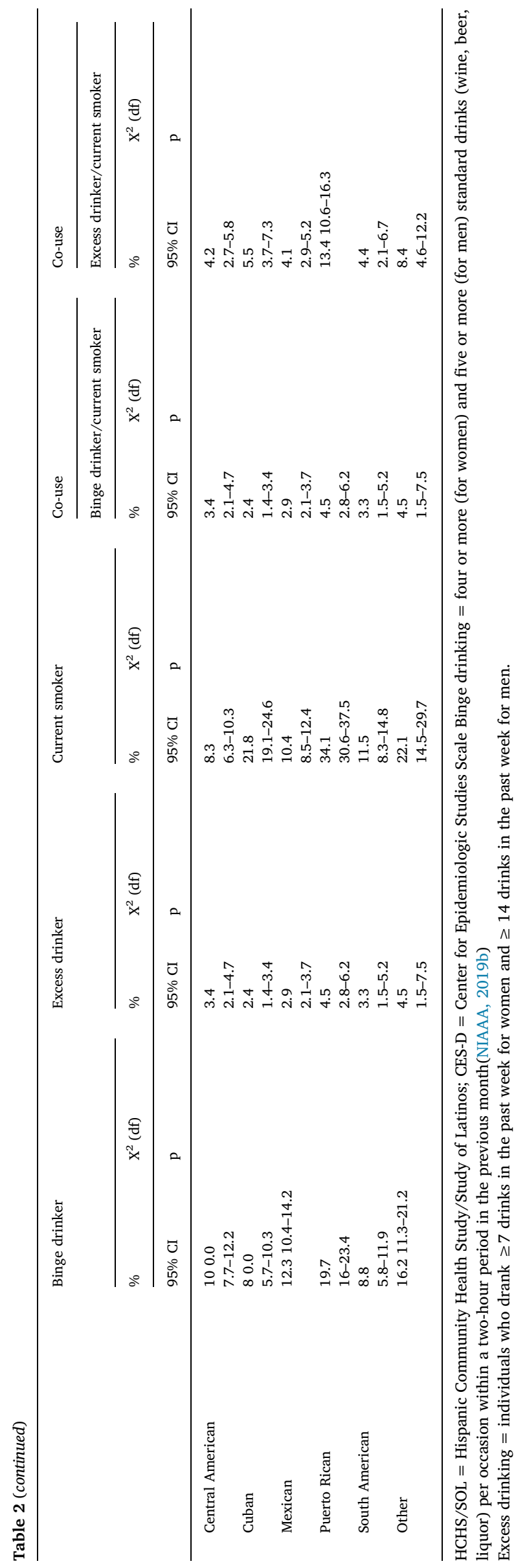

\section{Discussion}

In the present analysis of HCHS/SOL baseline data, we explored novel associations of co-use of at-risk alcohol consumption and smoking by persons of diverse Hispanic/Latino backgrounds. Our main finding was that Puerto Rican women were more likely to co-use alcohol in excess or binge patterns and smoke cigarettes than women of Mexican background. Furthermore, Dominican and Central American women also had higher odds of co-use excess alcohol and smoking compared to Mexican women. Of note, Central and South American men were less likely to co-use either binge drinking or excess drinking and smoking. Previous studies on the association between at risk alcohol consumption and cigarette smoking behavior among Hispanics/Latinos(Bandiera, Vaeth, Caetano, \& Perez-Stable, 2018; Woolard, Liu, Parsa, et al., 2015) were conducted only among persons of Mexican background.

We also found that neither language nor social acculturation measures in either men or women was associated with increased or decreased co-use of these substances. This lack of association of acculturation among women differs from that previously observed for prevalence of smoking alone (Marin et al., 1989; Perez-Stable et al., 2001), but most data point to inconsistent associations of smoking and acculturation among Hispanic/Latino men (Marin et al., 1989; PerezStable et al., 2001). These observations highlight important differences and similarities that need attention in developing prevention programs for Hispanics/Latinos with a special emphasis on both men and women of different heritage backgrounds.

Individuals in HCHS/SOL with significant depressive symptoms had higher odds to co-use smoking and binge drinking in both men and women. The importance of co-morbidity of mental health symptoms and at-risk alcohol use and smoking is highlighted by this finding and adds to the public health priority of addressing these issues in a comprehensive approach to manage substance use and mental health. There were gender differences in the association between physical activity and co-use of smoking and binge drinking or excess drinking. Specifically, physical activity was protective for women but a riskfactor for men. This underscores the importance of studying physical activity with substance use and highlights the need for future research to establish the mechanisms explaining the gender differences.

These HCHS/SOL analyses confirmed that at risk drinking was more prevalent among Puerto Ricans and Mexicans as in other studies (Caetano et al., 2009; Chartier \& Caetano, 2010; Ramisetty-Mikler et al., 2010; Vaeth, Caetano, Mills, \& Rodriguez, 2012). Given these data, it is not surprising that Puerto Rican women were more likely to both have higher smoking and at risk drinking prevalence (Caetano et al., 2009; Chartier \& Caetano, 2010; Ramisetty-Mikler et al., 2010; Vaeth, Caetano, Mills, \& Rodriguez, 2012). Thus, this study helps answer the discordance in smoking and drinking among Mexican and Cuban backgrounds and suggests that Hispanics/Latina women of Caribbean background may be more likely to co-use these two substances. This underscores our main finding in that co-use was more common among selected subpopulations of Hispanic/Latina women and not in men. This is especially important for social settings, such as bars and nightclubs, which still allow smoking where alcohol is sold in many states. Thus, public health efforts can be tailored to venues that serve alcohol and also allow smoking to prevent the co-use of these substances among Caribbean Hispanic/Latina women. Moreover, there were differences among men in that Central and South American men were more likely to co-use either binge drinking or excess drinking and smoking than Mexican men, which also highlights gender differences by nationality.

These findings are important for the field of substance use and for preventive and treatment interventions for Hispanics/Latinos by national background. It should be noted that the differences by national background were significant beyond control of multiple covariates, which included, age, gender, education, health insurance, marital status, acculturation, birthplace and physical activity. Thus, these 
Table 3

Odds ratios of co-use alcohol consumption and smoking in the target population of HCHS/SOL 2008-2011.

\begin{tabular}{|c|c|c|c|c|c|c|}
\hline & \multirow{2}{*}{\multicolumn{2}{|c|}{$\begin{array}{l}\text { Binge drinker/current smoker } \\
\text { OR }[95 \% \mathrm{CI}]\end{array}$}} & \multirow{2}{*}{\multicolumn{2}{|c|}{$\begin{array}{l}\text { Excess drinker/current smoker } \\
\text { OR }[95 \% \mathrm{CI}]\end{array}$}} & \multirow{2}{*}{\multicolumn{2}{|c|}{$\begin{array}{l}\text { Binge or excess drinker/current smoker } \\
\text { OR }[95 \% \mathrm{CI}]\end{array}$}} \\
\hline & & & & & & \\
\hline & Women & Men & Women & Men & Women & Men \\
\hline Age (years) & $0.9[0.9-0.9]$ & $0.9[0.9-0.9]$ & $0.9[0.9-0.9]$ & $0.9[0.9-1.1]$ & $0.9[0.9-0.9]$ & $0.9[0.9-0.9]$ \\
\hline \multicolumn{7}{|l|}{ Birthplace } \\
\hline US born & $1.8[1.1-3.0]$ & $1.0[0.6-1.6]$ & $2.0[1.0-3.9]$ & $1.1[0.4-2.6]$ & $2.0[1.2-3.2]$ & $1.0[0.6-1.6]$ \\
\hline Foreign born & 1.0 & 1.0 & 1.0 & 1.0 & 1.0 & 1.0 \\
\hline \multicolumn{7}{|l|}{ Depressive Symptoms } \\
\hline CESD $<10$ & 1.0 & 1.0 & 1.0 & 1.0 & 1.0 & 1.0 \\
\hline CESD $\geq 10$ & $1.5[1.1-2.2]$ & $1.5[1.2-2.0]$ & $2.3[1.3-3.9]$ & $1.5[1.0-2.2]$ & $1.5[1.1-2.2]$ & $1.5[1.1-2.0]$ \\
\hline \multicolumn{7}{|l|}{ Meets 2008 activity level guidelines } \\
\hline Yes & $0.8[0.5-1.3]$ & $1.5[1.1-2.2]$ & $0.8[0.5-1.3]$ & $1.3[0.7-2.3]$ & $0.8[0.5-1.2]$ & $1.5[1.1-2.1]$ \\
\hline No & 1.0 & 1.0 & & 1.0 & 1.0 & 1.0 \\
\hline \multicolumn{7}{|l|}{ Has current health insurance } \\
\hline Yes & 1.0 & 1.0 & 1.0 & 1.0 & 1.0 & 1.0 \\
\hline No & $0.9[0.6-1.5]$ & $1.5[1.1-1.9]$ & $0.9[0.6-1.5]$ & $1.6[1.0-2.6]$ & $1.0[0.7-1.5]$ & $1.5[1.2-2.0]$ \\
\hline \multicolumn{7}{|l|}{ Marital status } \\
\hline Single & $1.7[0.9-3.2]$ & $0.8[0.5-1.3]$ & $1.4[0.6-3.1]$ & $1.0[0.6-1.5]$ & $1.5[0.8-2.5]$ & $0.7[0.5-1.1]$ \\
\hline Married or living with a partner & $1.3[0.7-2.5]$ & $0.6[0.4-0.9]$ & $0.7[0.3-1.5]$ & $0.5[0.3-0.8]$ & $1.1[0.6-1.9]$ & $0.5[0.4-0.8]$ \\
\hline Separated, divorced, or widowed & 1.0 & 1.0 & 1.0 & 1.0 & 1.0 & 1.0 \\
\hline \multicolumn{7}{|l|}{ Education } \\
\hline No high school diploma or GED & 1.0 & 1.0 & 1.0 & 1.0 & 1.0 & 1.0 \\
\hline High school diploma/GED or greater & $0.8[0.5-1.2]$ & $0.6[0.4-0.8]$ & $0.7[0.3-1.3]$ & $0.7[0.4-1.0]$ & $0.7[0.5-1.1]$ & $0.6[0.4-0.8]$ \\
\hline \multicolumn{7}{|l|}{ Acculturation } \\
\hline Language & $1.1[0.9-1.4]$ & $1.1[0.9-1.3]$ & $1.0[0.7-1.4]$ & $1.1[0.8-1.5]$ & $1.1[0.9-1.4]$ & $1.1[0.9-1.3]$ \\
\hline Social & $1.2[0.8-1.6]$ & $0.9[0.7-1.1]$ & $1.3[0.8-2.1]$ & $0.7[0.4-1.1]$ & $1.2[0.9-1.6]$ & $0.9[0.7-1.1]$ \\
\hline Hispanic/Latino background group & 0.08 & $<0.01$ & $<0.0001$ & 0.1 & 0.03 & $<0.01$ \\
\hline Mexican & 1.0 & 1.0 & 1.0 & 1.0 & 1.0 & 1.0 \\
\hline Dominican & $1.5[0.7-3.3]$ & $0.5[0.2-1.1]$ & $7.7[2.2-26.1]$ & $0.6[0.2-2.2]$ & $2.0[0.9-4.3]$ & $0.5[0.2-1.0]$ \\
\hline Central American & $1.4[0.6-3.5]$ & $0.4[0.2-0.7]$ & $3.2[1.0-10.3]$ & $0.6[0.3-0.8]$ & $1.3[0.5-3.1]$ & $0.4[0.2-0.7]$ \\
\hline Cuban & $1.7[0.7-4.4]$ & $0.6[0.3-1.2]$ & $3.2[1.0-10.8]$ & $1.0[0.4-2.3]$ & $1.8[0.7-4.1]$ & $0.6[0.3-1.2]$ \\
\hline Puerto Rican & $3.2[1.5-6.6]$ & $1.2[0.7-1.9]$ & $6.0[2.2-16.5]$ & $1.5[0.7-3.3]$ & $3.4[1.7-6.8]$ & $1.1[0.7-1.8]$ \\
\hline South American & $1.7[0.7-4.1]$ & $0.3[0.1-0.8]$ & $1.0[0.2-4.0]$ & $0.1[0.02-0.8]$ & $1.6[0.6-3.7]$ & $0.3[0.2-0.7]$ \\
\hline Other & $1.8[0.7-4.5]$ & $0.6[0.2-1.4]$ & $5.3[1.8-14.9]$ & $1.1[0.2-4.9]$ & $1.6[0.6-4.0]$ & $0.6[0.2-1.4]$ \\
\hline
\end{tabular}

HCHS/SOL = Hispanic Community Health Study/Study of Latinos

CES-D = Center for Epidemiologic Studies Scale

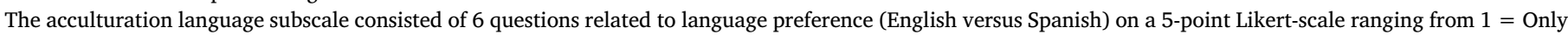
Spanish to $5=$ Only English and the responses are averaged to define a score. A higher score on the scale signifies higher language acculturation.

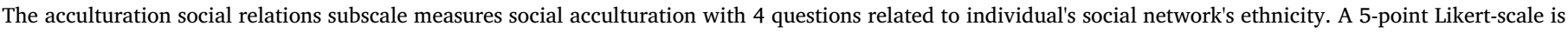

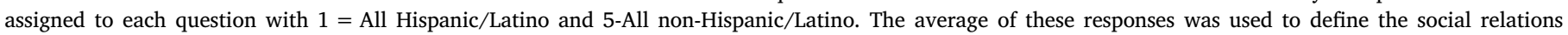
acculturation score. A higher score on the scale signifies higher social relations acculturation.

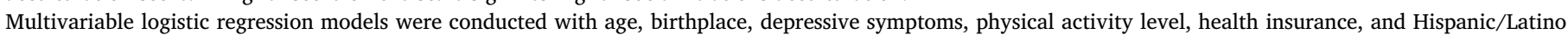
background group as independent variables and co-use of binge drinking and smoking and also excess drinking and smoking as dependent variables.

Bold indicates all ps $<0.05$.

differences are robust and point to directions for targeted interventions. As mentioned before, Hispanics/Latinos experience different prevalence of mental illness; and findings from this study suggest that targeted efforts should be focused on certain Hispanic/Latino national background groups regardless of mental health status. Further, targeted efforts can also focus on Hispanics/Latinos regardless of demographic factors, such as age, gender, socioeconomic status and birthplace. Thus, findings from this study suggest a global effort to focus on certain Hispanic/Latino subgroups. However, special precaution should be paid. Because of the large nature of the study and the use of secondary data, all variables that could contribute to differences by national background might not have been accounted for. For example, previous research noted that normative norms play an important role for Hispanics/Latinos, and thus, certain Hispanic/Latino national background groups might have more liberal attitudes (Vaeth et al., 2017; Zemore, 2005). Future research is needed to uncover the role of normative norms as well as other factors that may contribute to the findings.

There are limitations to this study. First, the data from this HCHS/ SOL analysis are cross-sectional limiting causal inference for the observations. Second, the alcohol consumption measure does not include diagnosis of alcohol abuse/dependence; and therefore, binge drinking, and excess drinking were reported as components of at-risk drinking. Third, the measure of acculturation was language and social relationsspecific and may not fully capture what the construct represents. Although the acculturation measure (SASH)(Marin et al., 1987) is widely used, it captures a unidimensional aspect of acculturation in which individuals are either more "Americanized" or more "Hispanic/ Latino" and therefore does not adequately measure a bicultural identity. Further, because of sample size limitations, all South American countries were collapsed into one heritage group, when South Americans could differ by country of family origin. HCHS/SOL has a large sample size of over 16,000 adults, but in stratified analyses by gender and Hispanic/Latino background co-use of alcohol and smoking rates were relatively low. Finally, HCHS/SOL is not nationally representative of the Hispanic/Latino population in the United States, given that we only sampled persons from four defined communities. Most national studies in the United States have a majority of Mexicans, since they are the largest Hispanic/Latino demographic group and thus, HCHS/SOL presents findings on other background groups that are understudied. HCHS/SOL individuals are predominantly immigrants and may not represent the behaviors of second and third generation Hispanics/Latinos.

In conclusion, our study highlights that among Hispanics/Latinos, 
women of Puerto Rican, Dominican, Central American and mixed background are more vulnerable to co-use of smoking and at-risk drinking. Treatment and preventive measures should mainly focus on co-use in different Hispanic/Latino background groups, since there were differences in the burden of these behaviors by Hispanic/Latino background.

Supplementary data to this article can be found online at https:// doi.org/10.1016/j.addbeh.2019.106087.

\section{Implications}

1. Studies of Hispanics/Latinos have mostly been of Mexican Americans although there are substantial differences co-use of smoking and drinking by heritage background.

2. Puerto Rican women had increased odds of co-use of smoking and binge or excess drinking compared to Mexican American women.

3. Treatment and preventive measures should mainly focus on co-use in different Hispanic/Latino background groups, since there were differences in the burden of these behaviors by Hispanic/Latino background.

\section{Acknowledgements}

This paper was initially written while Frank Bandiera was at the University of Texas School of Public Health and a recipient of a grant from the Robert Wood Johnson Foundation's New Connections program to study the interrelationships between smoking, alcohol, and mental health symptoms among Hispanics/Latinos.

\section{Funding}

The Hispanic Community Health Study/Study of Latinos, carried out as a collaborative study, was supported by contracts from the National Heart, Lung, and Blood Institute (NHLBI) to the University of North Carolina (N01-HC65233), University of Miami (N01-HC65234), Albert Einstein College of Medicine (N01-HC65235), Northwestern University (N01-HC65236), and San Diego State University (N01HC65237). The following Institutes/Centers/Offices contribute to the HCHS/SOL through a transfer of funds to the NHLBI: National Center on Minority Health and Health Disparities, the National Institute of Deafness and Other Communications Disorders, the National Institute of Dental and Craniofacial Research, the National Institute of Diabetes and Digestive and Kidney Diseases, the National Institute of Neurological Disorders and Stroke, and the Office of Dietary Supplements.

\section{Declarations of Competing Interest}

None. Although the author is an FDA Tobacco Regulatory Science Fellows at CTP, this work was not done as part of his/her official duties. This publication reflects the views of the author and does not represent agency position or policy.

\section{References}

Alegria, M., Mulvaney-Day, N., Torres, M., Polo, A., Cao, Z., \& Canino, G. (2007). Prevalence of psychiatric disorders across Latino subgroups in the United States. American Journal of Public Health, 97(1), 68-75.

Andresen, E. M., Malmgren, J. A., Carter, W. B., \& Patrick, D. L. (1994). Screening for depression in well older adults: Evaluation of a short form of the CES-D (Center for Epidemiologic Studies Depression Scale). American Journal of Preventive Medicine, 10(2), 77-84.

Bandiera, F. C., Arguelles, W., Gellman, M., et al. (2015). Cigarette smoking and depressive symptoms among Hispanic/Latino adults: Results from the Hispanic community health study/study of Latinos (HCHS/SOL). Nicotine \& Tobacco Research, 17(6), 727-734.

Bandiera, F. C., Vaeth, P. A. C., Caetano, R., \& Perez-Stable, E. J. (2018). The role of acculturation and binge drinking on smoking status among Mexican Americans: Comparison by border residence. Drug and alcohol dependence. 183, 205-209.

Bull, F. C., Maslin, T. S., \& Armstrong, T. (2009). Global physical activity questionnaire (GPAQ): Nine country reliability and validity study. Journal of Physical Activity \& Health, 6(6), 790-804.

Caetano, R. (1987). Alcohol use and depression among U.S. Hispanics. British Journal of Addiction, 82(11), 1245-1251.

Caetano, R., Ramisetty-Mikler, S., \& Rodriguez, L. A. (2009). The Hispanic Americans Baseline Alcohol Survey (HABLAS): The association between birthplace, acculturation and alcohol abuse and dependence across Hispanic national groups. Drug and Alcohol Dependence, 99(1-3), 215-221.

Chartier, K., \& Caetano, R. (2010). Ethnicity and health disparities in alcohol research. Alcohol Research \& Health: the Journal of the National Institute on Alcohol Abuse and Alcoholism, 33(1-2), 152-160.

Ejsing, L. K., Becker, U., Tolstrup, J. S., \& Flensborg-Madsen, T. (2015). Physical activity and risk of alcohol use disorders: Results from a prospective cohort study. Alcohol and Alcoholism, 50(2), 206-212.

Hallgren, M., Vancampfort, D., Lundin, A., Andersson, V., \& Andreasson, S. (2018). New steps for treating alcohol use disorder: The emerging importance of physical exercise. Psychopharmacology, 235(9), 2771-2773.

Jetelina, K. K., Reingle Gonzalez, J. M., Vaeth, P. A., Mills, B. A., \& Caetano, R. (2016). An investigation of the relationship between alcohol use and major depressive disorder across Hispanic National Groups. Alcoholism, Clinical and Experimental Research, 40(3), 536-542.

Kaplan, R. C., Bangdiwala, S. I., Barnhart, J. M., et al. (2014). Smoking among U.S. Hispanic/Latino adults: The Hispanic community health study/study of Latinos. American Journal of Preventive Medicine, 46(5), 496-506.

Khantzian, E. J. (1997). The self-medication hypothesis of substance use disorders: A reconsideration and recent applications. Harvard Review of Psychiatry, 4(5), 231-244.

Lavange, L. M., Kalsbeek, W. D., Sorlie, P. D., et al. (2010). Sample design and cohort selection in the Hispanic Community Health Study/Study of Latinos. Annals of Epidemiology, 20(8), 642-649.

Liu, S., Oshri, A., \& Duprey, E. B. (2018). Alcohol use and depressive symptoms among a nationally representative sample of youth investigated for maltreatment. Journal of Studies on Alcohol and Drugs, 79(3), 380-390.

Lui, P. P., \& Zamboanga, B. L. (2018). A critical review and meta-analysis of the associations between acculturation and alcohol use outcomes among Hispanic Americans. Alcoholism, Clinical and Experimental Research, 42(10), 1841-1862. https://doi.org/ 10.1111/acer.13845 Oct.

Marin, G., Perez-Stable, E. J., \& Marin, B. V. (1989). Cigarette smoking among San Francisco Hispanics: The role of acculturation and gender. American Journal of Public Health, 79(2), 196-198.

Marin GVM, B.; Otero-Sabogal, F.; Perez-Stable, E.J. Development of a short acculturation scale for Hispanics. Hispanic Journal of Behavioral Sciences 1987;9:183-205.

NIAAA. What's "at-risk" or "heavy" drinking? (2019). https://www.rethinkingdrinking. niaaa.nih.gov/How-much-is-too-much/Is-your-drinking-pattern-risky/Whats-AtRisk-Or-Heavy-Drinking.aspx (Accessed August 25, 2017).

NIAAA. Drinking Levels Defined. (2019). https://www.niaaa.nih.gov/alcohol-health/ overview-alcohol-consumption/moderate-binge-drinking (Accessed November 8, 2016).

Pavey, T. G., Gartner, C. E., Coombes, J. S., \& Brown, W. J. (2015). Assessing the effectiveness of High Intensity Interval Training (HIIT) for smoking cessation in women: HIIT to quit study protocol. BMC Public Health, 15, 1309.

Perez-Stable, E. J., Ramirez, A., Villareal, R., et al. (2001). Cigarette smoking behavior among US Latino men and women from different countries of origin. American Journal of Public Health, 91(9), 1424-1430.

Prapavessis, H., De Jesus, S., Fitzgeorge, L., Faulkner, G., Maddison, R., \& Batten, S. (2016). Exercise to enhance smoking cessation: The getting physical on cigarette randomized control trial. Annals of Behavioral Medicine, 50(3), 358-369.

Prochaska, J. J. (2011). Smoking and mental illness-Breaking the link. The New England Journal of Medicine, 365(3), 196-198.

Ramisetty-Mikler, S., Caetano, R., \& Rodriguez, L. A. (2010). The Hispanic Americans Baseline Alcohol Survey (HABLAS): Alcohol consumption and sociodemographic predictors across Hispanic national groups. Journal of Substance Use, 15(6), 402-416.

Sorlie, P. D., Aviles-Santa, L. M., Wassertheil-Smoller, S., et al. (2010). Design and implementation of the Hispanic Community Health Study/Study of Latinos. Annals of Epidemiology, 20(8), 629-641.

Vaeth, P. A., Caetano, R., Mills, B. A., \& Rodriguez, L. A. (2012). Alcohol-related social problems among Mexican Americans living in U.S.-Mexico border and non-border areas. Addictive Behaviors, 37(8), 998-1001.

Vaeth, P. A., Caetano, R., \& Rodriguez, L. A. (2012). The Hispanic Americans Baseline Alcohol Survey (HABLAS): The association between acculturation, birthplace and alcohol consumption across Hispanic national groups. Addictive Behaviors, 37(9), 1029-1037.

Vaeth, P. A., Wang-Schweig, M., \& Caetano, R. (2017). Drinking, alcohol use disorder, and treatment access and utilization among U.S. racial/ethnic groups. Alcoholism, Clinical and Experimental Research, 41(1), 6-19.

Woolard, R., Liu, J., Parsa, M., et al. (2015). Smoking is associated with increased risk of binge drinking in a young adult Hispanic population at the US-Mexico border. Substance Abuse, 36(3), 318-324.

Zemore, S. E. (2005). Re-examining whether and why acculturation relates to drinking outcomes in a rigorous, national survey of Latinos. Alcoholism, Clinical and Experimental Research, 29(12), 2144-2153. 